\title{
O que pode o ensino da educação física escolar em um centro socioeducativo de atendimento ao adolescente em conflito com a lei?
}

\author{
What can the teaching of school physical education in a \\ socioeducative center of adolescent care in conflict with the law?
}

Débora Nascimento ${ }^{1}$

Emanoele Lima Abreu²

\section{Resumo}

O Centro Socioeducativo de Atendimento ao Adolescente em Conflito com a Lei (CSE) é uma das 13 unidades do Instituto de Atendimento Socioeducativo do Espírito Santo (IASES). A partir de uma atuação no espaço escolar dessa unidade, com a disciplina de Educação Física, foram traçados os seguintes objetivos: analisar o projeto político-pedagógico do IASES, relatar a prática pedagógica adotada com a Educação Física e apontar possiveis caminhos neste contexto. Para isso, utilizou-se metodologia qualitativa e a pedagogia de projetos de Hernández (1998) para organização dos conteúdos a serem trabalhados com os alunos. Para a materialização desse relato de experiência foi registrado e descrito o espaço educacional do CSE. Na oportunidade, cerca de 140 alunos participaram das aulas, distribuídos em turmas do $1^{\circ}$ ao $9^{\circ}$ ano e uma turma de Ensino Médio. Ao longo de todo o processo coletamos alguns registros que serviram como instrumentos de avaliação, bem como a observação dos próprios docentes. Os resultados observados indicam que o

\footnotetext{
1 Mestranda em Educação Física (UFES), Especialista em Práticas Pedagógicas (UFOP) e Licenciada em Educação Física (UCV). Trabalha no Grupo Educacional Siena na Educação Infantil e Ensino Fundamental I e II. Foi Professora de Educação Física pela Secretaria de Estado de Educação (SEDU), especificamente no Centro Socioeducativo de Atendimento ao Adolescente em conflito com a Lei. Apresenta experiência no âmbito da educação formal e não-formal e se dedica aos estudos nas áreas de concentração: docência e processos educativos; Teorias e práticas pedagógicas da Educação Física.

2 Doutoranda em Ciências Ambientais (UFSCar), Mestra em Engenharia Ambiental (UFOP), Especialista em Gestão Ambiental (CEUT), Bióloga (UFPI) e Gestora Ambiental (IFPI). Trabalhou como Professora do curso Técnico em Controle Ambiental (CEAD/IFMG), do curso de Pós-Graduação em Práticas Pedagógicas (CEAD/UFOP) e do ensino básico do Estado de Minas Gerais.
}

Interfaces da Educ., Paranaíba, v.11, n.31, p. 21-42, 2020

ISSN 2177-7691 
O que pode o ensino da educação física escolar...

trabalho com a pedagogia de projetos e a interdisciplinaridade curricular, que possuem conhecimentos socialmente relevantes, enriqueceram as experiências discentes e, em especial, as docentes, possibilitando repensar e reconstruir suas práticas educacionais.

Palavras-chave: Educação física. Adolescente em conflito com a lei. Sistema socioeducativo.

\section{Abstract}

The Socio-Educational Center for Assistance to Adolescents in Conflict with the Law (CSE) is one of the 13 units of the Institute for Social and Educational Services of Espírito Santo (IASES). From the performance in the school space of this unit, with the discipline of Physical Education, the following objectives were outlined: to analyze the political-pedagogical project of IASES, to report the pedagogical practice adopted with Physical Education and to point out possible paths in this context. For that, it was used qualitative methodology and the pedagogy of projects of Hernández (1998) for organization of the contents to be worked with the students. For the materialization of this experience report, the educational space of the CSE was recorded and described. About 140 students participated in the classes, distributed in classes from the 1st to the 9th grade and a high school class. Throughout the process, we collected some records that served as assessment instruments, as well as the observation of the teachers themselves. The observed results indicate that the work with project pedagogy and curricular interdisciplinarity, which have socially relevant knowledge, enriched the experiences of students and teachers, making it possible to rethink and reconstruct their educational practices.

Keywords: Physical Education; Adolescent in conflict with the law; Socioeducational system.

\section{Introdução}

O Instituto de Atendimento Socioeducativo do Espírito Santo (IASES) iniciou seus trabalhos em 1967. Trata-se de uma autarquia com personalidade jurídica de direito público interno, com autonomia administrativa e financeira, vinculada à Secretaria de Estado de Direitos 
Humanos (SEDH) e mantida pelo Governo do Estado do Espírito Santo (IASES, 2015). O Centro Socioeducativo de Atendimento ao Adolescente em Conflito com a Lei (doravante CSE) localizado em Tucum, Cariacica-ES, é uma das 13 unidades do IASES, sendo considerada modelo no âmbito socioeducativo para o Estado e em nivel nacional.

O interesse em pesquisar um tema relacionado a esse sistema, surgiu a partir de uma atuação no espaço escolar como docente ${ }^{3}$ nas dependências do CSE. Em 2016, a Secretaria de Estado da Educação do Espírito Santo (SEDU), por meio da Gerência de Gestão de Pessoas (GEGEP), abriu o Edital de Processo Seletivo Simplificado $n^{\circ} 045 / 2016$ direcionado aos professores de diferentes áreas do conhecimento para trabalhar em Designação Temporária (DT) em escolas regulares e espaços com privação de liberdade. De acordo com as normas regidas no edital:

\begin{abstract}
O Secretário de Estado da Educação, no uso das atribuições que lhe foram conferidas pela Lei 3.043/75, e tendo em vista o disposto na Lei Complementar $n^{\circ} 115$, de 13 de janeiro de 1998 e alterações e à Lei $n^{\circ}$ 5.580 , de 13 de janeiro de 1998 e alterações e principalmente no art. $2^{\circ}$ da Lei Complementar $n^{\circ} 809$ de 24 de setembro de 2015, torna público pelo presente Edital, as normas para a realização do processo seletivo para admissão de professores habilitados em caráter temporário para atuação na educação básica: nos níveis de Ensino Fundamental e Ensino Médio, nas modalidades de Educação de Jovens e Adultos, Educação Escolar Quilombola, Educação em Espaços de Privação de Liberdade (Unidades Prisionais, Unidades Socioeducativas), Educação Especial, Programas/Projetos, no Ensino Regular da rede pública estadual para o ano letivo de 2017 (EDITAL DE PROCESSO SELETIVO SIMPLIFICADO N045/2016).
\end{abstract}

Nesse ínterim, primeiramente, identificamos que o trabalho se justifica pela necessidade de informações no campo da formação inicial, de modo que se torna cada vez mais comum vermos professores de educação física pontuarem como possibilidade de espaço de atuação as escolas regulares de ensino, os projetos sociais e esportivos, as empresas de lazer, dentre outros. No entanto, é incomum que esses profissionais tenham conhecimento acerca das unidades socioeducativas ou prisionais.

\footnotetext{
${ }^{3}$ Vale notar que um dos autores deste trabalho atuou como professor pela Secretaria de Estado de Educação do Espírito Santo (SEDU), ministrando atividades específicas na educação básica pública estadual, especificamente, no CSE, no período de fevereiro de 2017 a maio de 2018 .
}

Interfaces da Educ., Paranaỉba, v.11, n.31, p. 21-42, 2020 
O que pode o ensino da educação física escolar...

Em consequência disso, os professores da área têm pouco interesse em optarem pelo trabalho nessas unidades, o que também foi oportuno para nossa motivação em pesquisar especificamente sobre esse tema. Exemplo disso, é a experiência profissional, como já citamos anteriormente, de um dos autores deste trabalho que, após aprovação no edital de processo seletivo $n^{\circ}$ 045/20164, optou por atuar no CSE. Nesse certame, disputou vagas com apenas 09 profissionais da área, tendo em vista que, fora do sistema prisional, as inscrições são consideravelmente maiores.

O que comprova esse argumento é a lista de aprovação geral dos candidatos do mesmo edital divulgada no site do Governo do Estado do Espírito Santo através do sistema de seleção de designação temporária. A classificação para professor de educação física no campo de atuação ensino fundamental, ensino médio, EJA segundo segmento e EJA ensino médio das escolas regulares, escolas de tempo integral, classes hospitalares e atendimento domiciliar, apenas para o Municipio de Cariacica, foram de 205 classificados.

Por fim, a partir da revisão bibliográfica, verificou-se que apesar de existirem trabalhos na área da psicologia e educação a respeito das experiências vivenciadas com adolescentes no contexto socioeducativo (ARAGÃO; MARGOTTO; BATISTA, 2012; ARANZEDO, 2006; BAZON; SILVA; FERRARI, 2013), essa temática não é recorrente em periódicos consolidados da área educação física ${ }^{5}$, sobretudo trabalhos focados na percepção dos alunos ou nas explanações sobre as unidades do IASES (GOMES, 2018).

A materialização desse relato de experiência esteve ancorada nos seguintes objetivos: analisar o projeto político-pedagógico do IASES e relatar a prática pedagógica adotada com a educação física dentro do CSE, bem como apontar possiveis caminhos nesse contexto.

Com base nisso, realizamos através da análise do Projeto Politico Pedagógico Institucional (PPPI), um levantamento das funções do IASES. Em

\footnotetext{
${ }^{4}$ Nesse ano o Governo do Estado do Espírito Santo adotou a realização de prova objetiva para selecionar os candidatos.

5 Movimento (Revista de Educação Física da UFRGS); Motrivivência (Revista de Educação Física, Esporte e Lazer) e Revista Brasileira de Ciências do Esporte.

Interfaces da Educ., Paranaíba, v.11, n.31, p. 21-42, 2020
} 
seguida, foi apresentada informações gerais acerca do CSE. Posteriormente, buscamos refletir sobre a transformação didático-pedagógica do esporte e o quanto esse processo tem potencial para impactar na educação física dentro dos seus possiveis campos de atuação.

Este trabalho é fruto de uma experiência profissional a partir da pedagogia de projetos de Hernández (1998) no contexto socioeducativo do Espírito Santo e pretende contribuir para a produção de conhecimentos no âmbito da educação física presente no sistema socioeducacional.

\section{Revisão de literatura}

\subsection{A Socioeducação no Espírito Santo: O IASES e o seu Projeto Político Pedagógico Institucional (PPPI)}

Apresentaremos neste tópico o que é, e qual a função do IASES, assim como a avaliação de alguns dos principais pontos abordados no Projeto Político Pedagógico Institucional (PPPI), documento que rege a organização, isto é, que orienta as ações na esfera do atendimento socioeducativo no estado.

No PPPI, disponibilizado no website do IASES, encontramos a seguinte definição:

O IASES é uma autarquia pública, com personalidade jurídica de direito público interno, com autonomia administrativa, técnica e financeira, vinculada à Secretaria de Estado da Justiça, que tem por finalidade formular, implementar e manter o sistema de atendimento responsável pela execução das medidas socioeducativas no Estado do Espírito Santo (SECRETARIA DE ESTADO DA JUSTIÇA INSTITUTO DE ATENDIMENTO SOCIOEDUCATIVO DO ESPÍRITO SANTO, 20-. p. 03).

O PPPI do IASES orienta as ações cotidianas com a intenção de realizar a Missão Institucional que preconiza:

Promover a socioeducação do adolescente a quem se atribui autoria de ato infracional por meio da gestão participativa da política de atendimento socioeducativo no Espírito Santo, sustentada nos princípios dos direitos humanos e em conjunto com o Sistema de Garantia de Direitos (SECRETARIA DE ESTADO DA JUSTIÇA INSTITUTO DE ATENDIMENTO SOCIOEDUCATIVO DO ESPÍRITO SANTO, 20-. p. 14).

Interfaces da Educ., Paranaíba, v.11, n.31, p. 21-42, 2020 
O que pode o ensino da educação física escolar...

O Estatuto da Criança e do Adolescente (BRASIL, 1990, p. 47) conceitua o Ato Infracional como sendo: "Art. 103. Considera-se ato infracional a conduta descrita como crime ou contravenção". Por sua vez, Slaibi e Gomes (2013, p. 405) descrevem o crime como:

[...] Derivado do latim crimen (acusação, queixa, agravo, injúria) em acepção vulgar, significa toda a ação cometida com dolo, ou infração contrária aos costumes, a moral e a lei, que é igualmente punida, ou que é reprovada pela consciência [...].

Nesse sentido, a filosofia da instituição busca estar em consonância com as diretrizes do Estatuto da Criança e do Adolescente (ECRIAD) e do Sistema Nacional de Atendimento Socioeducativo (SINASE).

O IASES apresenta 16 competências específicas, pleiteadas no artigo $4^{\circ}$ do Decreto 1.583-R de 18 de novembro de 2005, que aprova o Regulamento do Instituto tendo como $1^{\mathrm{a}}$ competência:

I - Formular a política estadual de atendimento ao adolescente em conflito com a lei, em consonância com a legislação pertinente e orientada pelos princípios do respeito à dignidade da pessoa humana, aos direitos humanos, à equidade e à justiça social. (SECRETARIA DE ESTADO DA JUSTIÇA INSTITUTO DE ATENDIMENTO SOCIOEDUCATIVO DO ESPÍRITO SANTO, 20-. p. 03).

O mesmo órgão também é responsável pela gestão e execução das medidas socioeducativas em 13 unidades nas regiões Norte, sul e metropolitana do Espírito Santo. O público alvo são adolescentes que se encontram nessa limitação cumprindo atendimento de três formas: meio fechado, semiliberdade e meio aberto. Assim, o Projeto Politico Pedagógico Institucional é o documento norteador dos métodos e técnicas dos projetos pedagógicos de cada uma das 13 unidades de sua responsabilidade (SECRETARIA DE ESTADO DA JUSTIÇA INSTITUTO DE ATENDIMENTO SOCIOEDUCATIVO DO ESPÍRITO SANTO, 20-).

Cabe ressaltar que existem outros documentos normativos necessários a organização específica de cada unidade. São eles: 
Politica de Monitoramento das Unidades Socioeducativas de Meio Fechado em Gestão Direta; Programa Institucional de Segurança; Programa Institucional de Saúde; Programa Institucional de Meio Aberto; Programa Institucional de Semiliberdade; Programa Institucional de Abordagem Familiar e Comunitária; Programa de Egressos; Política de Gestão de Pessoas; Regimento Interno Institucional; Fluxograma de Alvarás e Transferências entre Unidades Socioeducativas; Padronização do Formato dos Prontuários, dos Diagnósticos Polidimensionais, dos Planos Individuais de Atendimento e dos Relatórios Avaliativos; Manual do Agente Socioeducativo; Manual de Orientações Técnicas; Caderno de Diretrizes em Educação Básica; Caderno de Diretrizes em Educação Profissional; dentre outros (SECRETARIA DE ESTADO DA JUSTIÇA INSTITUTO DE ATENDIMENTO SOCIOEDUCATIVO DO ESPÍRITO SANTO, 20-. p. 07).

Esses documentos permeiam as ações diárias voltadas aos adolescentes no decorrer de seu cumprimento da medida socioeducativa, que funcionam como uma maneira de responsabilizá-lo com intuito de não reincidir nas condutas delituosas. Portanto, é preciso dar maior visibilidade a essa diligência, bem como a outros temas voltados aos setores educacional, familiar, cultural, social e político que cerca a vida desses adolescentes.

Alguns trabalhos confirmam a necessidade de evidenciar esses espaços, bem como prescrevem distintos fatores que vão muito além do atendimento socioeducativo no Estado (VOGAS, 2018; CONCEIÇÃO, 2016; GOES et al., 2012), como possiveis colabores para a relação de adolescentes com o cometimento de diferentes crimes.

Muitas melhorias e conquistas ainda precisam ser alcançadas dentro desse meio, assim como sabemos que a responsabilidade do Estado não está em realizar medidas paliativas e em última instância, ao contrário, é preciso fazer valer o direito de todas as classes, independentemente de sua condição.

Consideramos imprescindivel as conclusões de Silva (2019) em sua tese de doutorado, onde ele destaca que investimentos e planejamentos podem ser um caminho para superar desafios dentro dos espaços socioeducativos e garantir o direito à educação aos socioeducandos.

\subsection{O Centro Socioeducativo de Atendimento ao Adolescente em Conflito com a Lei (CSE)}

O CSE é uma construção modelo na área socioeducacional a nível nacional. Segundo a Secretaria Especial dos Direitos Humanos:

Interfaces da Educ., Paranaíba, v.11, n.31, p. 21-42, 2020 


\begin{abstract}
Em 2004, o Governo do Estado propôs ao Governo Federal a construção do Centro Socioeducativo de Internação (CSE), cujo projeto arquitetônico foi planejado em consonância a uma proposta pedagógica que previa a divisão de fases de acordo com o crescimento pessoal do adolescente. O projeto foi aprovado, dando origem a um convênio com a Subsecretaria de Promoção dos Direitos da Criança e do Adolescente da Secretaria Especial dos Direitos Humanos da Presidência da República. A unidade foi entregue em 2008 (SECRETARIA DE ESTADO DA JUSTIÇA INSTITUTO DE ATENDIMENTO SOCIOEDUCATIVO DO ESPÍRITO SANTO, 201-, p. 18).
\end{abstract}

Nesse período, a gestão da Unidade era realizada pela Associação Capixaba de Desenvolvimento e Inclusão Social (ACADIS), por intermédio de um Contrato de Gestão sendo este o primeiro a ser firmado no estado do Espírito Santo no quesito de contratualização por resultados. Após ser aprovado no Processo Seletivo Simplificado citado anteriormente, um dos proponentes deste trabalho foi convocado a conhecer a escola cuja matriz fica situada em Cariacica Sede, de responsabilidade Estadual e atende alunos em ensino regular do fundamental ao médio.

Ademais, dentro do CSE encontra-se um espaço escolar e um anexo da filial de Cariacica Sede, onde documentos, matrículas e outras burocracias são realizados. Todavia, a diferença que se tem, é que os adolescentes em medida socioeducativa são obrigatoriamente matriculados e acompanham as aulas dentro dessa escola localizada nas dependências do CSE.

O CSE dispõe de casas que são divididas por etapas do processo de cada adolescente, sendo um total de sete moradias comportando quatorze meninos cada uma delas. Para além dessas, tem-se duas casas denominadas de Motivação, duas de Reconhecimento, duas de Aprofundamento e uma de Projeto de Vida.

A Casa Motivação é a primeira a recebê-los na unidade. Nela é explicada todas as normas e projeto daquela repartição. Nessa etapa os educandos só podem fazer o deslocamento escola-moradia passando sempre em frente a portaria, sendo cumprida ordem de que andem em fila indiana, braços para trás, um braço de distância um do outro e sem levantar a cabeça. Esses comandos são adotados como medida de segurança. 
É importante ressaltar que cada moradia tem suas regras, características e singularidades. Por exemplo, na Casa Motivação, os adolescentes ficam um período de quarenta e cinco (45) dias. Existem três etapas distintas em que os mesmos passam nessa casa: na primeira, chamada de "ajuste", é obrigatório o uso de camisas amarelas. Na segunda, conhecida como "acoplamento", a camisa usada é de cor azul. Por fim, a terceira, a "segurança", a camisa utilizada é a verde.

Quando o adolescente avança para a segunda casa, chamada de "Reconhecimento", ele já pode usar roupas "da rua" como eles próprios costumam caracterizá-las. Já na última casa, "Projeto de Vida”, eles adquirem a liberdade de irem para seus dormitórios mais tarde, usar relógio, dentre outras necessidades que os próprios adolescentes desejam avançar no processo para chegar nessa etapa.

Nesse local os agentes socioeducativos, pedagogos, assistência social, psicólogos, gerentes da unidade (administrativo e de segurança) compõe a equipe multidisciplinar e fazem o acompanhamento diário dos educandos.

\subsection{A transformação didático-pedagógica do esporte como possibilidade de intervenção no âmbito escolar e no sistema socioeducativo}

A educação física, como disciplina obrigatória no currículo escolar, nasceu na Europa no final do século XVIII e início do século XIX. Como aponta Soares (1996, p. 08), “com a fundação dos chamados Sistemas Nacionais de Ensino, a Ginástica, primeira definição dada à Educação Física e com caráter bastante abrangente, teve lugar como conteúdo escolar obrigatório". De acordo com Bracht (1999), essa disciplina foi muito influenciada pela medicina e instituição militar.

Foi exatamente entre a década de 1970 e 1980 onde novas propostas foram geradas em contraposição ao paradigma da aptidão física, que surge o Movimento Renovador6 buscando reflexões e contribuições com teor mais crítico e reflexivo que se engajavam em questões sociais e pedagógicas, "muito

6 Para compreender melhor o movimento "humanista" na pedagogia (um dos movimentos renovadores da Educação Física), indicamos a leitura do livro Metodologia do ensino da educação física, de um Coletivo de Autores (1992).

Interfaces da Educ., Paranaíba, v.11, n.31, p. 21-42, 2020 
O que pode o ensino da educação física escolar...

influenciadas pelas ciências humanas, principalmente a sociologia e a filosofia da educação de orientação marxista” (BRACHT, 1999, p. 10).

Com o intuito de romper com a lógica esportiva e da aptidão física nas aulas de educação física, a abordagem crítico-emancipatória foi proposta pelo professor Elenor Kunz, da Universidade Federal de Santa Catarina (DARIDO, 2003).

A pedagogia de Paulo Freire (1992), por sua vez, influenciou suas primeiras produções. Outra forte influência, segundo BRACHT (1999, p. 80) é as "[...] Análises fenomenológicas do movimento humano com base, em parte, em Merleau-Ponty, tomadas de estudiosos holandeses como Gordjin, Tamboer, e também Trebels".

Embora tivesse ampla divulgação nos trabalhos em educação física, em pesquisa realizada em 2013, os professores Ghidetti, Almeida e Bracht (2013) destacam os estudos fenomenológicos como necessários para contribuir e viabilizar as possibilidades presentes na teoria do se movimentar humano.

Com uma nova perspectiva, Kunz se esforça a nos apresentar seus apontamentos não apenas no âmbito teórico, mas, também, exemplos práticos com o esporte. Ele salienta sua visão acerca deste fenômeno e como é preciso considerá-lo para seu trato didático no ambiente escolar:

\begin{abstract}
O fenômeno social do esporte, para poder ser transformado numa atividade de "interesse real" a todos os participantes, deve ser compreendido na sua dimensão polissêmica. Isso significa que compreender o esporte nessa dimensão deve abranger, também, conforme Brodtmann/Trebels (1979): 1. Ter a capacidade de saber se colocar na situação de outros participantes no esporte, especialmente daqueles que não possuem aquelas "devidas" competências ou habilidades para a modalidade em questão; 2 . Ser capaz de visualizar componentes sociais que influenciam todas as ações socioculturais no campo esportivo (a mercantilização do esporte, por exemplo); 3. Saber questionar o verdadeiro sentido do esporte e por intermédio dessa visão crítica poder avaliá-lo (KUNZ, 2009, p. 29).
\end{abstract}

Há um trato diferenciado com esse conteúdo, pois ele não se reduz ao movimento específico de dada modalidade, mas avança positivamente ao possibilitar a participação de todos os alunos com suas particularidades. Percebe-se a capacidade que o campo social tem de influenciar na cultura de cada ambiente e para além, necessariamente, tem-se o esforço de mostrar aos Interfaces da Educ., Paranaîba, v.11, n.31, p. 21-42, 2020 
alunos critérios de avaliação crítica a respeito deste elemento, "o esporte". Ademais, é válido que esse processo estabeleça uma ação comunicativa entre professor-aluno, aluno-professor e aluno-aluno.

Nesse sentido, percebemos que uma visão reducionista que vise apenas à execução do movimento de dada modalidade esportiva foge dos objetivos centrais do currículo escolar, não colaborando para uma ampliação do repertório de movimento dos alunos e para sua autonomia e emancipação diante das práticas experimentadas.

\section{Metodologia}

O presente trabalho utiliza uma pesquisa qualitativa, esta, segundo Gil (1994, p. 02), supõe que existe uma vinculação entre o sujeito e o mundo que, muitas vezes, não consegue ser traduzida em números. Também se trata de uma pesquisa descritiva, onde analisou-se os dados indutivamente (GIL, 1994, p. 02). Portanto, para a análise dos dados obtidos, os instrumentos estatísticos não se fazem necessários, tem-se como consenso que, para o objetivo desta pesquisa, perder aspectos importantes relacionados à condição humana dos sujeitos, suas impressões, sensações e sentidos pode ser um equívoco.

Classifica-se também como uma pesquisa exploratória, pois tem como fundamento "[...] modificar conceitos e ideias, tendo em vista a formulação de problemas mais precisos ou hipóteses pesquisáveis para estudos posteriores" (GIL, 2008, p. 27). Utilizou-se, ainda, a pedagogia de projetos de Hernández (1998) e, para a materialização do nosso relato de experiência, acessamos o espaço educacional do CSE.

As aulas de educação física aconteceram nas dependências dessa unidade e lá contamos com quadra esportiva, campo gramado, piscina, sala de lutas, salas de aula, auditório e biblioteca. No período matutino, que corresponde ao horário escolar, cerca de 140 alunos participam das aulas de 50 minutos cada e são atendidos com o calendário escolar regular designado pelo Estado, ou seja, os dias letivos estipulados para as escolas fora do sistema socioeducativo são os mesmos para os alunos que cumprem medida. 
O que pode o ensino da educação física escolar...

A quantidade de aulas e de disciplinas também segue o currículo base escolar estadual. Porém, a rotatividade de professores é grande e, com isso, os estudantes perdem aulas no período em que não há professor e, posteriormente, essas aulas não são repostas. As salas de aula são distribuídas conforme o quantitativo de alunos, tendo um limite de 20 pessoas por sala, tendo em vista os motivos de segurança, diferentemente do contexto fora do sistema socioeducativo. Durante o ano de 2017, até maio de 2018, a escola possuía uma sala "multidisciplinar" com alunos matriculados do $1^{\circ}$ ao $5^{\circ}$ ano escolar; duas turmas de $6^{\circ}$ ano, duas de $7^{\circ}$ ano, uma de $8^{\circ}$ ano, uma de $9^{\circ}$ ano e uma turma de Ensino Médio (com alunos do $1^{\circ}$ ao $3^{\circ}$ ano estudando juntos).

A escola dispunha de uma sala de professores, uma copa pequena para momento de lanche dos agentes socioeducativos, uma sala reduzida para reserva de alguns materiais escolares e mais duas extras que eram destinadas ao atendimento pedagógico, psicológico, assistente social, gerência e distintas necessidades. O espaço contava com um auditório para utilização em aulas com os adolescentes, atendimentos, reuniões, curso de formação para os agentes, confraternizações, eventos escolares, dentre outras possibilidades.

Fora desse ambiente escolar, existe a estrutura para esporte e lazer com a presença de uma quadra esportiva, um campo gramado, uma sala de lutas com sanitários e bebedouros próximos e uma piscina, que poderiam ser utilizados para aulas de educação física e as demais disciplinas dependendo da permissão do setor de segurança da unidade.

Os instrumentos selecionados para agregar ao processo e aos resultados da pesquisa foram: a) registros das experiências a partir de um projeto de intervenção (plano de ensino e planos de aula) com avaliação escrita, estes elaborados antes da intervenção respeitando os propósitos da pesquisa, bem como, estando anexados como documentação de práticas; b) registros imagéticos pelos representantes do IASES; c) observação dos comportamentos e falas em meio ao contexto; d) diálogos com os alunos; e) anotações no Diário de Campo das principais conversas nos momentos de aula para captar as expectativas, o retorno da aula, as indagações, dificuldades, dúvidas, sugestões, impressões dos alunos - elemento primordial, referente aos Interfaces da Educ., Paranaíba, v.11, n.31, p. 21-42, 2020 
registros dos acontecimentos relevantes de cada aula, para a organização das escolhas dos conteúdos e metodologias que podem ser adotadas e alteradas a partir destas anotações, dinamizando e preparando o decorrer de todo o processo (OLIVEIRA; NASCIMENTO, 2014).

As imagens aqui utilizadas foram cedidas pelo IASES e encontram-se em seu website. A gerência da unidade registrou as fotos e publicou no website divulgando o evento realizado. A identidade dos alunos foi resguardada. $\mathrm{Na}$ contratação da equipe foi assinado um termo que permite o uso de imagem para o IASES.

\section{Relato de Experiência}

\subsection{A atuação em designação temporária no CSE com a disciplina de Educação Fisica}

Nesta seção descreveremos a sequência didática desenvolvida no decorrer do ano letivo. A definição dos temas foi realizada após um primeiro contato com os alunos, dessa forma, eles poderiam resgatar os conteúdos já vistos fora do sistema socioeducativo e quais atividades gostariam de realizar no ano.

A maioria optou pela prática do futsal (termo pouco conhecido pelos educandos), por conta disso, propomos iniciarmos com esse conteúdo. Essa iniciativa foi completamente válida, pois quando os alunos tiveram acesso as regras e fundamentos dessa modalidade, para alguns, eram informações novas.

Neste momento analisamos o quanto eles estavam carentes de novas experiências. Segundo Basso et al. (2015. p. 97):

\footnotetext{
Os alunos têm grande inclinação para fazer aulas de Educação Física por diversos motivos, mas quase nunca relacionados a aprender um saber sistematizado sobre o corpo e movimento. Até porque com frequência desconhecem este objetivo, que é pouco anunciado[...]. Este fato também está implícito na fala dos alunos, que vão "fazer Educação Física" e não "estudar Educação Física" como se referem aos componentes curriculares como Física e Química.
}

É nesse viés, que o "querer jogar futebol" está relacionado a "rolar bola", jogar por jogar ou cumprindo regras básicas, como muitos vão conhecendo e Interfaces da Educ., Paranaíba, v.11, n.31, p. 21-42, 2020 
se apropriando através de outras vivências no cotidiano (BASSO et al. 2015). Há uma ausência, portanto, de comprometimento com outros conhecimentos relacionados a modalidade, tais como a história, posicionamentos, regulamento, nome e treino dos fundamentos, sistema defensivo e ofensivo.

Aproveitamos para dialogar sobre o significado desse esporte, haja vista que, a partir da "tradição" que se tem na educação física de não realizar uma autorreflexão pedagógica, algumas iniciativas tornam-se dificultosas, questionáveis e até inusitadas para alguns alunos (VAZ et al. 2009).

Por intermédio dessa avaliação diagnóstica nas primeiras aulas com cada turma, decidimos iniciar com um conteúdo próximo ao que os alunos já tinham afinidade e ampliar os seus conhecimentos sobre dada modalidade. Em seguida seria proposta uma prática nunca vivenciada por nenhum dos estudantes da escola. Sendo assim, foi elaborado o seguinte cronograma de conteúdo para ser trabalhado no decorrer do ano (quadro 1).

Quadro 1 - Cronograma anual de conteúdos (2017/2018)

\begin{tabular}{|c|c|c|c|}
\hline $1^{\circ}$ trimestre (2017) & $2^{\circ}$ trimestre (2017) & $3^{\circ}$ trimestre (2017) & $1^{\circ}$ trimestre (2018) \\
\hline $\begin{array}{l}\text { História do futebol } \\
\text { mundial }\end{array}$ & $\begin{array}{c}\text { História dos jogos e } \\
\text { das brincadeiras }\end{array}$ & $\begin{array}{c}\text { Capacidades fisicas: } \\
\text { noções gerais }\end{array}$ & Avaliação diagnóstica \\
\hline $\begin{array}{c}\text { Características, } \\
\text { fundamentos e regras } \\
\text { do futsal }\end{array}$ & $\begin{array}{l}\text { Característica dos } \\
\text { jogos (diferente de } \\
\text { esporte) }\end{array}$ & $\begin{array}{l}\text { As atividades físicas e } \\
\text { os exercícios físicos: } \\
\text { implicações na } \\
\text { obesidade e no } \\
\text { emagrecimento }\end{array}$ & $\begin{array}{c}\text { História e } \\
\text { curiosidades }\end{array}$ \\
\hline $\begin{array}{l}\text { Princípios básicos de } \\
\text { ataque e defesa } \\
\text { (sistema } 2+2 \text { e } 3+1 \text { ) }\end{array}$ & Jogos pré-desportivos & $\begin{array}{c}\text { Substâncias nocivas } \\
\text { ao organismo. Ou seja, } \\
\text { substâncias que } \\
\text { podem causar dano ao } \\
\text { corpo }\end{array}$ & $\begin{array}{c}\text { Regras básicas e } \\
\text { Posições e funções } \\
\text { dos jogadores }\end{array}$ \\
\hline $\begin{array}{c}\text { O que é Fair Play e } \\
\text { Fristyle }\end{array}$ & $\begin{array}{c}\text { Jogos populares, } \\
\text { cooperativos, de mesa } \\
\text { e de raciocínio }\end{array}$ & $\begin{array}{c}\text { Esportes de Aventura } \\
\text { e o cuidado com a } \\
\text { Natureza: vivenciamos } \\
\text { skate, long e slackline. }\end{array}$ & Jogos coletivos \\
\hline $\begin{array}{c}\text { Características e } \\
\text { regras do Tag Rugby }\end{array}$ & & & $\begin{array}{c}\text { Realização de torneio } \\
\text { Interclasse }\end{array}$ \\
\hline
\end{tabular}

Fonte: produção própria. 
Ao final do primeiro trimestre propomos a vivência de uma nova modalidade: o Tag Rugby, um jogo de iniciação ao Rugby. Além de ampliar as experiências dos alunos, o propósito era conhecer e experimentar um novo esporte coletivo de quadra, com sua história, características, regras e movimentos específicos.

No trimestre seguinte, propomos novos jogos e brincadeiras que tinham por objetivo resgatar e vivenciar os diferentes jogos populares, tradicionais, de regras, de mesa e com rede divisória. Nessa experiência, realizamos as brincadeiras: bolinha de gude, pique bandeira, travinha, ping-pong (com mesa e rede adaptadas), dentre outras.

No terceiro trimestre, com os conteúdos relacionados às capacidades físicas, nossa intenção era propor o conhecimento físico básico do corpo humano (força, resistência, velocidade, equilíbrio, agilidade e flexibilidade) e analisar seus atributos e como podem ser trabalhadas para manutenção da saúde. Em conjunto com essas ideias exploramos as noções acerca dos Esportes de Aventura e o cuidado com o Meio Ambiente.

Conforme citado na metodologia, em todas as aulas contemplávamos os conteúdos conceituais, procedimentais e atitudinais (DARIDO e SOUZA Jr., 2011). Como exemplo disso, trabalhamos no "esportes de aventura" sobre o conhecimento conceitual, as categorias do slackline (longline, highline, waterline e trickline) e as possibilidades de realizar os diferentes esportes de aventura no Espírito Santo. Nesse processo, também conhecemos nomes específicos dos equipamentos de segurança, curiosidades, regras das modalidades e outras particularidades ainda não observadas pelos alunos.

Em relação aos procedimentos, executamos skate, long e slackline em espaços alternativos do CSE. Já com os conhecimentos atitudinais, resgatamos o respeito ao meio ambiente, aos parceiros de interação e dialogamos sobre o tempo designado ao lazer na contemporaneidade e a necessidade do cuidado com os limites do nosso corpo.

O desenvolvimento das aulas se dava em diferentes espaços da escola: a quadra e o campo foram reservados para os esportes e jogos, enquanto que o gramado, para o slackline. Ademais, fora da escola exploramos o asfalto e seus pequenos morros para a prática do long; no auditório, jogamos ping-pong Interfaces da Educ., Paranaíba, v.11, n.31, p. 21-42, 2020 
O que pode o ensino da educação física escolar...

com mesa adaptada (e, também, dentro das moradias, considerando que foram doadas duas mesas oficiais de tênis para nosso uso), e, finalmente, as aulas teóricas com uso de recursos de computador e datashow nas salas de aulas, além do jogo de bolinhas de gude que eram feitos em frente ao auditório em espaço aberto.

Geralmente um ou dois agentes socioeducativos acompanhavam nossas aulas, especialmente quando eram na quadra tendo a possibilidade de até três agentes estarem presentes nas práticas. Isso ocorria em razão do deslocamento pela unidade: sair de um espaço fechado, a escola, para locais mais abertos, como quadra ou campo. Sendo assim, por motivos de segurança, esse quantitativo de agentes era alterado. Entretanto, no período de chuvas, devido a falta de cobertura da quadra realizávamos atividades dentro de sala de aula.

No início de 2018, sugerimos o handebol. Nesse período também foi proposto à realização do projeto ${ }^{7}$ de um torneio Interclasse. Os destaques indispensáveis dessas aulas visavam o ampliamento do repertório cultural dos alunos (por meio de uma modalidade pouco explorada nesse espaço escolar); conhecer as regras e fundamentos básicos do handebol; valorizar o espírito esportivo para a realização da interclasse e respeitar as diferenças individuais dos parceiros de interação.

IMAGEM 01: Interclasse de handebol com participação de árbitro convidado.

7 Durante o período de atuação na escola, com a disciplina de educação física, foram realizados dois projetos interdisciplinares: o projeto "Interclasse de Handebol" realizado em conjunto com a disciplina de biologia, e o projeto denominado "Negro Sou" desenvolvido com intuito de valorização do ser negro no Brasil, em consonância com a disciplina de história.

Interfaces da Educ., Paranaíba, v.11, n.31, p. 21-42, 2020 


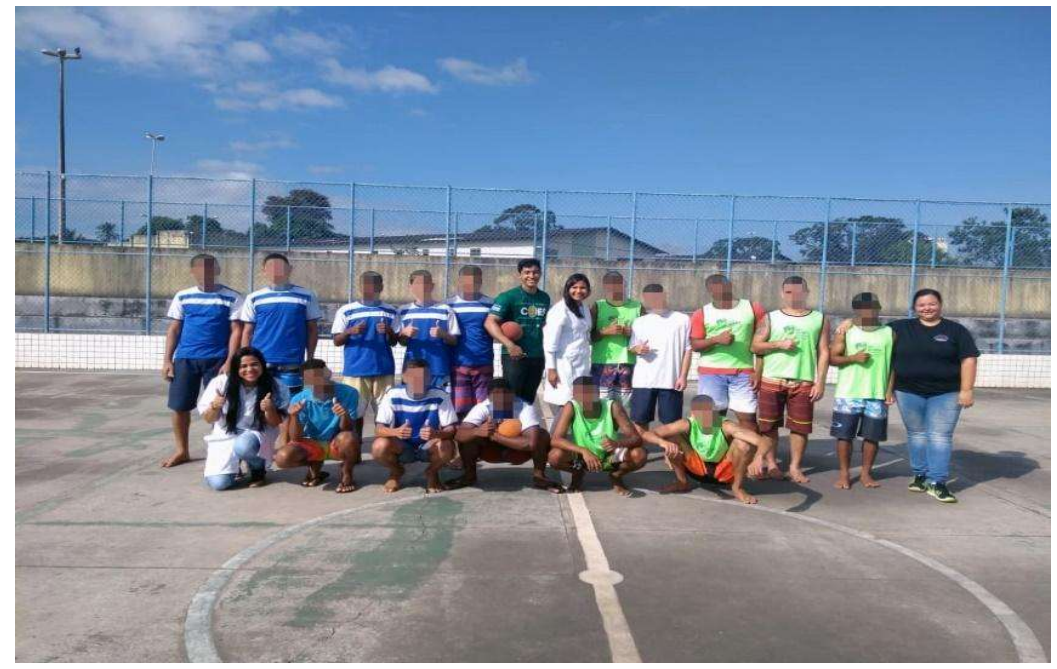

Fonte: www.iases.es.gov.br

IMAGEM 02: partida de handebol do $8^{\circ}$ ano $\mathrm{X} 9^{\circ}$ ano

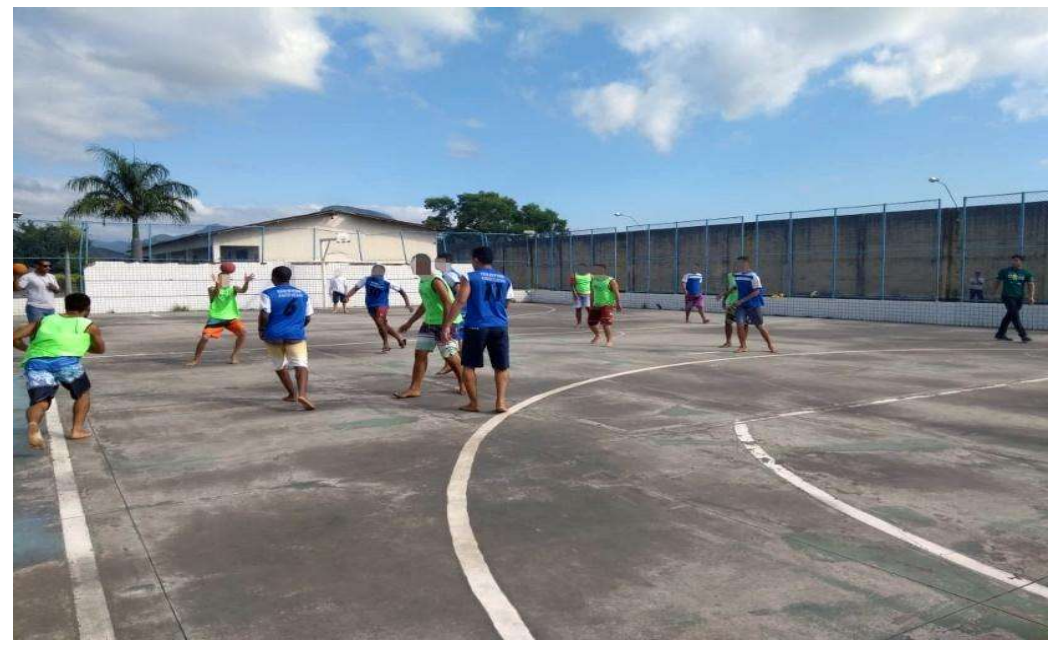

Fonte: www.iases.es.gov.br

Adotamos como metodologia a abordagem crítico-emancipatória de Kunz (2014), visto que sua proposta busca possibilitar a participação de todos os alunos com suas propriedades e percebe a capacidade que o âmbito social tem de influenciar na cultura de cada ambiente. Outrossim, é válido situarmos que esse processo se estabelece através da ação comunicativa entre professoraluno, aluno-professor, aluno-aluno onde verificamos que,

[...] o aluno enquanto sujeito do processo de ensino deve ser capacitado para sua participação na vida social, cultural e esportiva, o que significa não somente a aquisição de uma capacidade de ação funcional, mas a capacidade de conhecer, reconhecer e problematizar

Interfaces da Educ., Paranaíba, v.11, n.31, p. 21-42, 2020 
O que pode o ensino da educação física escolar...

sentidos e significados nesta vida, através da reflexão crítica (KUNZ, 2014, p. 31).

O autor explica que, para além do trabalho produtivo (treino de habilidades técnicas), precisamos nos atentar a mais dois elementos: a interação social e linguagem, de forma que "não só a linguagem verbal ganha expressão, mas todo o 'ser corporal' do sujeito se torna linguagem, a linguagem do 'se-movimentar' enquanto diálogo com o mundo" (KUNZ, 2013, p. 37).

Propomos aos alunos o processo de "compreender, experimentar e transformar o esporte" (COSTA; KUNZ, 2013,p. 125) e rompemos com a visão de que apenas jovens saudáveis e talentosos possam se ajustar as exigências práticas e terão sucesso em competições esportivas.

Utilizamos como instrumento de avaliação a observação das atitudes dos alunos em cada aula executada, tanto no aspecto motor, quanto em suas relações afetivas e cognitivas. Observamos, ainda, suas interações nas rodas de conversa, dúvidas e questionamentos, bem como o entendimento sobre os objetivos da aula e regras de cada atividade e jogo.

\section{Considerações finais}

Por meio deste trabalho, buscamos tematizar as diferentes manifestações da cultura corporal, com os conhecimentos conceituais, procedimentais e atitudinais de cada conteúdo (DARIDO E SOUZA JUNIOR, 2011) como um dos nossos objetivos principais. Para que isso ocorresse, foram realizadas diferentes estratégias metodológicas para alcançar a participação dos alunos e diversificar as aulas. Os registros e observações realizados em todo o processo, como instrumentos de avaliação, possibilitaram ressignificar as práticas.

Procuramos contribuir com a discussão sobre a presença da disciplina de educação física em uma Unidade Socioeducativa no Estado do Espírito Santo, haja vista que ainda são poucas as produções acadêmicas que abordam as potencialidades da disciplina dentro desse contexto educacional. Por fim, encontramos responder a seguinte questão: o que pode o ensino da 
educação física escolar em um centro socioeducativo de atendimento ao adolescente em conflito com a lei?

A pergunta motivadora desta pesquisa nos leva a considerar outros aspectos relevantes para pensarmos a educação física em unidades de privação de liberdade: as experiências de vida de tantos jovens e a sua cidadania, pois, a partir da possibilidade de estar presente no cotidiano de uma unidade socioeducativa, foi possivel notar que é preciso o Estado oferecer suporte aos adolescentes para além do período que eles permanecem internados.

Não há dúvidas de que precisamos de investimento nas unidades socioeducativas no estado do Espírito Santo. Entretanto, é preciso investimento, antes, durante e depois do acesso de tantos adolescentes a esse espaço, tendo como premissa, ações voltadas as camadas da sociedade mais vulneráveis, necessitadas de ações qualificadas nos serviços públicos. Ações essas que precisam ser tomadas como prevenção para não incidência e reincidência nos ambientes socioeducativos.

Existem boas práticas sendo adotadas, mas, o que se faz necessário e urgente é o fortalecimento e valorização de forma central e duradoura, isso no âmbito organizacional da unidade e no docente, pois o fazer de cada profissional afeta de forma direta a vida e a formação de cada adolescente que passa por aquele espaço.

Especificamente sobre a educação física, é preciso reforçar a identidade escolar principal que é a de disciplina, onde apenas profissionais qualificados possam ser responsáveis pelos momentos de aula com os alunos. Em outras palavras, não cabe a um profissional da área oferecer momentos de lazer, mas, sim tornar esses momentos de estudo e aprendizado mais agradáveis a partir das diferentes possibilidades de movimento presente no acervo da educação física. Assim, conseguimos intervir e afirmar que a modalidade pode fortalecer sua identidade de importância dentro do espaço escolar e no sistema socioeducativo.

Concomitantemente, conclui-se que o trabalho com a pedagogia de projetos (HERNÁNDEZ, 1998) e a interdisciplinaridade curricular, que possuem conhecimentos socialmente relevantes (BRACHT, 2011), Interfaces da Educ., Paranaíba, v.11, n.31, p. 21-42, 2020 
O que pode o ensino da educação física escolar...

enriqueceram as experiências discentes e, em especial, as docentes, possibilitando repensar e reconstruir suas práticas educacionais.

\section{Referências}

ARAGÃO, E. M. A.; MARGOTTO, L. R.; BATISTA, R.. Uma cidade-internação e suas multipli(cidades): encontros com adolescentes em cumprimento de medida socioeducativa. Revista EPOS, Rio de Janeiro, v. 3, n. 2, p. 01-21, julho-dezembro de 2012 .

ARANZEDO, A. C. "Nem anjos, nem demônios..." Adolescentes autores de homicidio: contexto do delito e representações sociais sobre a vida humana. Dissertação (Mestrado em Psicologia) Programa de Pós-Graduação em Psicologia da Universidade Federal do Espírito Santo, Vitória, 2006.

BASSO, 1.; CATTUZZO, M. T.; OllVEIRA, D. S. S.; FREUDENHEIM, A. M. A motivação dos alunos para as aulas de Educação Física: considerações e implicações para a atuação docente no ensino fundamental. In: CORREIA, W. R; RODRIGUES, B. M. Educação Física no Ensino Fundamental: da inspiração à ação. São Paulo: Fontoura, 2015.

BAZON, M. R.; SILVA, J. L. da; FERRARI, R. M. Trajetórias escolares de adolescentes em conflito com a lei. Educação em revista, Belo Horizonte, v. 29, n. 02, p. 175-199, jun de 2013.

BRACHT, V. A constituição das teorias pedagógicas da educação física. Cadernos Cedes, [S.1], XIX, n 48, p. 69-88, ago. 1999.

BRACHT. V. Dilemas no Cotidiano da Educação Física Escolar: entre o desinvestimento e a educação pedagógica. Salto para o futuro, Ano XXI, Boletim 12, v. 21, n. 11, Set. 2011.

BRASIL. Lei federal $n^{\circ} 8.069$ de 13 julho de 1990. Dispõe sobre o ESTATUTO DA CRIANÇA E DO ADOLESCENTE, e dá outras providências. Diário Oficial [da] República Federativa do Brasil, Brasília, DF, 14 jul. 1990. Disponivel em: <http:/ / www2.camara.leg.br/legin/fed/lei/1990/lei-8069-13-julho-1990372211-publicacaooriginal-1-pl.html> Acesso em: 22 out. 2018. 
CONCEIÇÃO, J. S. Notas sobre a presença da Educação Física no processo de ressocialização de adolescentes em conflito com a lei. 2016. Trabalho de Conclusão de Curso - Faculdade Católica Salesiana do Espírito Santo, Vitória, 2016.

COSTA, A. R.; KUNZ, E. Esporte Na Escola: Conhecer, experimentar e transformar. Revista Em Aberto - INEP, v. 26, p. 119-129, 2013.

DARIDO, S. C. Educação física na escola: questões e reflexões. Rio de Janeiro: Guanabara Koogan, 2003.

DARIDO, S. C.; SOUZA Jr., O. M. Para ensinar educação física: possibilidades de intervenção na escola. 7 ed. São Paulo: Papirus, 2011.

FREIRE, P. Pedagogia da Esperança. 5a edição. Rio de Janeiro: Paz e Terra, 1992.

GIL, A. C. Métodos e técnicas de pesquisa social. 6. ed. São Paulo: Atlas, 2008. GOES, D. C. et al. Características de jovens e adolescentes que entram no instituto de atendimento sócio-educativo do espírito santo. Núcleo de Informação do Sistema Socioeducativo, Vitória, 2011. Disponível em: <http://www.iases.es.gov.br/download/Artigo_NINF.pdf>. Acesso em: 01 out. 2014.

GHIDETTI, F. F.; ALMEIDA, F. Q. ; BRACHT, V. A presença da fenomenologia na/da teoria do semovimentar humano (TSMH) brasileira. Pensar a Prática (UFG. Impresso), v. 16, p. 886-902, 2013.

HERNÁNDEZ, F. Transgressão e mudança na educação: os projetos de trabalho. Porto Alegre: ArtMed, 1998.

IASES. Instituto de Atendimento Socioeducativo do Espírito Santo. O Iases. ES: 2015. Disponível em: <https://iases.es.gov.br/quem-somos-2>. Acesso em: 01 Abr, 2018.

KUNZ, E. Transformação Didático-Pedagógica do Esporte. 8a. Ed. Ijuí: Unijuí, 2014.

OLIVEIRA, S T.; NASCIMENTO, D. O estágio como possibilidade de aprendizado teórico e prático. In: V CONGRESSO SUDESTE DE CIÊNCIAS DO ESPORTE. 5 ., Lavras, MG Anais... Lavras: UFLA, 2014, p. 1-3.

SECRETARIA DE ESTADO DA JUSTIÇA INSTITUTO DE ATENDIMENTO SOCIOEDUCATIVO DO ESPÍRITO SANTO. Governo do Espírito Santo. Projeto Interfaces da Educ., Paranaíba, v.11, n.31, p. 21-42, 2020 
O que pode o ensino da educação física escolar...

Político Pedagógico Institucional do IASES, [20-]. Disponivel em: <https://iases.es.gov.br/Media/iases /Arquivos/PPPI_VERSAO_FINAL_1.pdf >. Acesso em 23 Set. 2018.

SLAIBI, F. N.; GOMES, P. P. V. Vocabulário Jurídico. 30. ed. Rio de Janeiro: Forense. 2013.

SILVA, K. C . A garantia do direito à educação para adolescentes e jovens em cumprimento de medida socioeducativa de internação. Tese de doutoramento. Programa de Pós-Graduação em Educação da Universidade Federal de Pernambuco (PPGE/UFPE). Recife, 2019.

SOARES, C. L. Educação física escolar: Conhecimento e especificidade. Revista Paulista de Educação Física, São Paulo, n. 2, p. 06-12, 1996.

VAZ, A. F. et al. Educação física em classe hospitalar: notas sobre uma experiência com uma turma de primeiros anos do ensino fundamental. Cadernos de Educação, Pelotas, n. 33, p. 167-184, 2009.

VOGAS, V. Atenção, candidados! Precisamos falar do IASES: O sistema socioeducativo do Espírito Santo grita por socorro há anos. O que o próximo governo estadual fará a esse respeito?. GazetaOnline, Vitória. 09 set. 2018. Politica. p. 30 Disponível em :< https://www.agazeta.com.br/colunas/vitorvogas/atencao-candidatos-precisamos-falar-do-iases-0918> Acesso em: 10 dez. 2019. 